\title{
Representing Asian Australianness in 2020 ... one soap opera at a time 中文
}

Edition 5, 2021

Dr Mridula Nath Chakraborty

DOI: 10.37839/MAR2652-550X5.21

中文 (Chinese translation)

What did one traffic light say to another? 'Don't look, I'm changing.' Blink and you miss it. This cheesy one-liner could be accused of referring to the transforming face of Australian-produced TV soap operas, the genre that Professor Lesleyanne Hawthorne identifies as 'a modern version of the morality play' that 'implicitly and explicitly' transmits messages about "the nature of Australian society, including the acceptability of ethnic diversity'.

Ask most people about the television series most identifiable with Australia, the chances are that they will mention Home and Away, Australia's most successful popular culture export (next only to its predecessor, Neighbours), marketed in at least 80 countries, and currently broadcast in nine. Set in a fictional town called Summer Bay, the land of eternal sunshine and nary a bush fire, the location is just far away enough from the chaotic confusion and confronting foreignness of capital cities like Sydney and Melbourne, a factor used to explain (or 'excuse') its lack of 'even an Italian Pizza Parlour, a Chinese restaurant, a Greek or a Lebanese milk bar'. Running since 1988, the soap opera's motley collection of fostered children, 'abandoned by [their] natural family, leaving [them] free to identify as 100 percent Australian in terms of language, culture and personal style' is a snapshot of the imagined community of 'pre-mass migration vision of Australia, peopled with unassailably Anglo citizens'. So much so that more than quarter of a century later, in 
2015, writer Benjamin Law (The Family Law and Waltzing the Dragon), in an article titled 'When Asians attack' in The Monthly, remarks that 'despite the fact that by 1990 roughly a third of all new immigrants were Asian' and by 2010, 'even though just over 10 percent of Australians identify as having Asian ancestry, all-white main casts are still common' in this colonial settler nation's cultural imagination and mediascape.

If the trans-millennial years between 1990 and 2010 were diagnosed by Professor Michael Wesley in There Goes the Neighbourhood: Australia and the Rise of Asia as 'a charmed double-decade of riches, openness and increasing safety' for Australians, they also paradoxically witnessed its peoples 'so complacent about how their country relates to the world, so incurious about how the world is changing, and so unprepared to think about how all of this will affect them'. Ten years later, nowhere is this baffling want of interest, in the wider world in which Australia has a stake, witnessed more than in the lack of awareness of Asian Australian presence and portrayal in mainstream media and the arts sphere. Note that I do not say that Asian Australianness is not available on our airwaves, galleries, screens or theatres; rather, in an age of hyper-connectivity and availability of global cultural material, the neglect of home-grown Asian Australian content and talent becomes markedly acute. One could evoke the infamous and age-old cultural cringe factor to explain the roots of such oversight, but to continue to do so at a time when Asia is constantly, definitely, and for all foreseeable futurity, on the horizon as well as within our borders, this obliviousness should be cause for concern with regards to Australia's self-positioning in the region.

On the one hand, Bali is commonplace in Australian imagination as a backyard for consumer tourism; on the other, the multifarious histories of Asian settlement in Australia, as depicted in its popular cultures, remain obscure to all but those who seek it strenuously and determinedly. The last decade, in particular, has witnessed a burgeoning of Asian Australian story-telling in our mediascapes, specifically about our histories of arrival on this unceded Aboriginal land, that provide the allimportant caveat and corrective to hegemonic white-settler nationalism. As Senator 
Penny Wong remarked to former Race Discrimination Commissioner Tim Soutphommasane in Mongrel Nation:

The first thing is probably to recognise that Asia is part of our history and who we are. So I think the construction of who we are, if we think of ourselves as just some sort of outpost of British colonialism, we're always going to be in a bit of trouble, aren't we, in terms of engaging with our region?

In the last decade, as the influence of Asia has announced itself in every possible way in Australia, from inbound migration (international students, temporary skilled workers, economic migrants) to outbound markets (Australia's coal, agricultural and aquatic produce, cultural products), Asian Australian storytelling has come to occupy an integral space at least in the imaginaries of our (i.e. in Asian Australian) communities. But its uptake, both lay and critical, in the mainstream and dominant space of institutionalised 'whiteness' has remained scant.

Such a negligent response of 'sanctioned ignorance' to the presence of Asia-inAustralia has immediate and long-term repercussions for Australia-in-Asia. At one time, Asian Studies was the preferred academic means to make Australians Asialiterate, in the old Colombo Plan manner of acquiring deep expertise in Asian countries and cultures, languages and societies, peoples and world views. This approach, paradoxically, has had the effect of putting Asia definitively outside, and other to, the imaginative borders of Australia, even as the nation was increasingly aligned in the geopolitical region. It obscured the arrivals and affinities that existed between Asia and Australia from at least 250 years ago, when Chinese and Indian entrepreneurs entered the realm and made it their own. Under the New Colombo Plan, the focus remains externalised: sending Australians out to Asia, which while necessary perhaps to acquaint ourselves with the new face of Asia, comes at the expense of the considerable knowledge base that exists within Australia itself among Asian Australian lineages. In the age of hypermobility, COVID-19 notwithstanding, and what sociologist and philosopher, Zygmunt Baumann, calls liquid modernity, the earlier 'otherising' division and distance between Asia and Australia is no longer 
possible. People, places and phenomena are connected via enhanced and faster means of travel (COVID-19 aside), new tropes of transnational migration, technologies that make it possible to exist simultaneously in several time-zones and popular culture participation across multiple contexts and languages, e.g. through Google Translate, or common platforms like YouTube, where a globalised synchrony of cultural expression can make K-Pop or Bollywood a household commodity, available at the click of your mouse.

There has been some scholarship in the insistence upon, and implications of, Asia literacy in Australian policy and governance matters. As scholars note, the overwhelmingly economic rationale routinely provided to equip Australians to 'deal' with the influence of Asia (including in former Prime Minister Julia Gillard's White Paper on Australia in the Asian Century) is one of the predominant reasons why Australians are deemed to 'need' literacy in Asia. The constantly vacillating and contradictory pivoting of Australia as it imagines itself in the region (from looking north so as to be part of the Asian region to turning west and becoming Indo-Pacific) also stands in complex negotiation with the 'idea' of Asia itself, as a 'region for our times' that came into geo-political prominence and reorganisation in the wake of World War II. Asia literacy clearly has to be navigated in Australia through the entwined approaches of what has been termed the twin prongs of 'Australia-in-Asia' and 'Asia-in-Australia'. Herein lies the problem of gauging Asia literacy as a skill set, to be obtained just through languages and cultures rather than story-telling. As Indigenous societies have emphasised again and again, Indigenous epistemologies are revealed through story telling. However, when it comes to Australia's other 'Others', i.e. its marked migrant-settlers of non-Anglo-Celtic origin, and Asians in the twenty-first century, the only recourse possible has been the ethnicity-based model of non-Anglophone speech, as evidenced in acronyms like NESB (Non-English Speaking Background), LOTE (Languages Other Than English), CALD (Culturally and Linguistically Diverse) etc.

In this scenario, Asian Australians serve both as the link to that supercontinent to our north, arbitrarily termed 'Asia' through colonial mechanisms of nomenclature, 
and as the separate entity that distinguishes us from our 'Asian looking' neighbours in Asia, whose lineages we may share, but cannot be assumed to inhabit in the same lingual or socio-political spheres. In this respect, Asian Australians are both a bridge and not to Asia. This is an important distinction that tends to get lost both in discourses of Asian Studies and governmental policies: Asian Australians can often be misrecognised as cognates of Asians, conduits to Asia or consumers of Asian products. While all three attributions have elements of truth in them, they are not the only distinguishing factors of Asian Australianness. In fact, as Mark Wang, deputy chairman of the Museum of Chinese Australian History in Melbourne asserts, 'We are about Australian history. We're not about Chinese history.' However, in the racially-charged fallout of situations such as the one created by the COVID-19 pandemic, the conflation of Asians and Asian Australians become particularly problematic.

The burden of representation falls on Asian Australians to demonstrate the histories of arrival that might justify their Asian sensibilities, while maintaining their own legitimacy as fair dinkum Australians. In the face of dominant representations of Australianness as Anglo-Celtic, it falls on to them to trace and narrate the indelible, but invisible-ised, chronicling of early Asian incursions and presences in Australia that testify to their belonging to this land as unquestionably as white settlers. In this scenario, it becomes all the more important to take note of Asian Australian stakes in media and popular culture so that we can tell the story of contemporary Australia and persuade the world within, and out there, that we are indeed worthy of our multicultural appellation vis-à-vis Asia. That our Asianness is not something that is just part and parcel of a culinary exotica made familiar, à la Masterchef, or in an equal and opposite demonisation, cause for the needle of suspicion to descend when the COVID-19 pandemic hit our lives. This is when popular culture can be a critical aid to understand the razor's edge on which Asian Australian experiences and identities rest, and which make us an integral narrator of the various strands of settlements that characterise this settler colony.

In the last five years, there has been an impassioned debate in the Australian public 
sphere about the lack of Asian Australian representation on our screens and influenced by benchmarking reports like Seeing Ourselves: Reflections of Diversity on Australian TV drama and Shifting the Balance: Cultural Diversity in Leadership Within the Australian Arts, Screen and Creative Sectors. Unbeknownst to most Australian television watchers, now hooked to platforms like Netflix, Amazon, HBO Now and iTunes for foreign content, diversity has been slowly, but surely creeping into our living rooms in the shape of The Principal, The Unlisted, The Hunting, and even the much-critiqued Here Come the Habibs. In 2020, an interesting mix of multicultural content hit our screens: Hungry Ghosts, a four-part supernatural drama brought home the trauma of the Vietnam war with a cast of more than 30 Asian Australian actors and 325 Asian Australian extras in an Australian TV first. The ever popular Masterchef got a two-in-one representation of diversity in Melissa Leong (female and of Asian descent) and conversations about race and diversity governed the reviews. 2021 promises more fun in Aftertaste, a six-part comedy drama where a world-famous "angry white guy" has to find a new narrative in smalltown Australia that already has its star restaurant run by an Asian young turk who had suffered racially-charged abuse while apprenticing under the celebrity chef.

However, I want to make a particular case for the soap opera that often does not have the same kind of artistic legitimacy as other media forms, and thus enters popular discourse via hoi polloi or low brow appreciation. By having such a broadbased appeal, especially in the context of the anti-intellectual bias that sees the ABC being attacked regularly, the soap opera in Australia can have unusual power to transform entrenched bias against those who are perceived to be outsiders to the dominant white settler narrative. Enter The Heights. A home-grown gem, it should rightly alter the Home and Away face of an Australia consumed the world over and replace it with what contemporary down-under in the Asian neighbourhood actually looks like. At least in its urban milieu, such a representation could possibly become an advertisement, and a shining new example, of its arrived-of-age multicultural diversity. It is important to make the point that it is in the genre of the soap opera that one stands to make the most of such diversity, unlike the longer-standing 
contenders to the label, viz. Home and Away and Neighbours. The Heights has been broadcast in the UK, but it should be a no-brainer that is precisely among our Asian neighbours that the show needs to be disseminated. The series is produced by Matchbox Pictures, the powerhouse television and film company co-formed by Tony Ayers (the Portuguese-Macau-born Australian creative and showrunner) and others, created by Warren Clarke and Que Minh Luu (Netflix director of local originals in Australia, previously executive producer at the Australian Broadcasting Corporation). This new kid on the block of television dramas exemplifies the relationship of Australia to its region in the Asian Century. The show premiered in 2019, with a follow-up second season broadcast throughout the COVID-19 pandemic period in 2020, but whether it has been renewed for a third season is yet unknown.

Arcadia Heights, the inner-city neighbourhood setting of the program, is as diverse as it could get, but ever so nonchalantly and matter-of-factly, with six families plotting the main storyline and a secondary cast of characters criss-crossing them depending on the trajectory of themes. Shot in Perth rather than the usual suspects of Melbourne and Sydney, the series is anchored, in equal parts, by The Railway, its local pub, and Dông Hu'o'ng, the Vietnamese corner grocery store. Both establishments are run by iron-fisted and sharp-tongued ladies, Hazel Murphy essayed with characteristic aplomb by the seasoned actress, Fiona Press whose career has spanned 37 years, and Iris Tran, played by first time debutant and refugee advocate, Carina Hoang, whose family fled Vietnam by boat in 1976, and lived in the Galang refugee camp in Indonesia. The pub has been a longstanding feature of soap operas, viz. the British Coronation Street, which has clocked more than 10,250 episodes since 1960, and demonstrates the changing face of Britain using the ruse of the local bar. In the case of The Heights, the Vietnamese corner store occupies equal billing, and is actually shot in the real Ton Sian Grocery in Northbridge that was established 37 years ago and bears witness to the way in which urban spaces have been transformed by such migrations.

The characters of The Heights live in social housing, The Towers, amidst a rapidly gentrifying neighbourhood, and value judgements notwithstanding on either side, 
manage to have a mostly friendly association, and even find love across the lines in sand. While the Murphys and the Davies provide their versions of dysfunctional family dramas, the Trans and the Jafaris offer cohesiveness of a refugee ethos that stands in stark contrast to some of the other neighbours' shenanigans. Residents of European as well as Asian descent are shepherded by Indigenous Elders, Uncle Max and Aunty Pam, and other central First Nations characters like Mich and Leonie. Any tensions that exist between the denizens of this imagined community are washed over by an impossibly seamless co-existence that is as realistic as it is aspirational. The show manages to tick all the 'issues' boxes without seeming to: Indigeneity, ethnicization, disability and class are cut across by a story board that manages to spotlight the difference between public and private schools, homosexuality in minority communities, games that local politicians play, the pitfalls of compulsive gambling and drug addiction, teenage sex education, and of course the numerous romps in bed that are de rigueur for soap operas. In all of this, the narrative does not waver from its utter commitment to diversity in its true sense of the word. Surely it behoves Australian audiences to pay attention to this drama unfolding within our shores to get a sense that while we were fighting the history wars and indulging in identity politics, our neighbourhoods and suburbs had quietly but surely transformed into something quintessentially Asian Australian. The fate of Season 3 of The Heights seems to be in question, but it would be a real shame if such a powerful medium is allowed to quietly wither away without the kind of funding and viewership that would make it a real Australian television icon of the twenty-first century.

Image: an exhibit marking 50 years of television in Australia. Credit: Glenn Brown/Flickr. 